\title{
Discriminación laboral de la mujer afrocolombiana*
}

\author{
María Del Mar Moreno** \\ (Maria.moreno4@correo.icesi.edu.co)
}

Artículo de reflexión recibido el 2/10/2015 y aprobado el 19/11/2015.

\begin{abstract}
Cómo citar este artículo:
MORENO, María del Mar (2015). "Discriminación laboral de la mujer afrocolombiana”. En: Trans-pasando Fronteras, Núm. 8, pp. 119-123. Cali, Colombia: Centro de Estudios Interdisciplinarios, Jurídicos, Sociales y Humanistas (CIES), Facultad de Derecho y Ciencias Sociales, Universidad Icesi.
\end{abstract}

DOI: $10.18046 /$ retf.i8.2228

Todo comenzó, el 15 de abril de 2015, tras asistir a una actividad que se realizaba en la asociación Casa Cultural el Chontaduro, Cali-Colombia, donde una mujer de la organización presentó una ponencia. Ésta, empezaba con una pregunta muy puntual: ¿Qué es la mujer? A la que posteriormente respondió “la mujer es parte fundamental de la sociedad. No obstante, ésta no sabe apreciarnos. Nos excluye en diversos ámbitos, más aun si somos mujeres afro. Por ejemplo, en el campo laboral nos pagan y nos hacen trabajar más que a las mujeres blancas". 1

Esta respuesta, me indignó. Es decir, ¿por qué estas mujeres deben trabajar más por menos? ¿No que la esclavitud ya se había acabado? ¿A qué se debe dicha discriminación laboral?

* Escrito elaborado en el marco del curso Integración y Exclusión Social del Departamento de Estudios Sociales de la Universidad Icesi, Cali, Colombia.

** Estudiante de Ciencia Política y Sociología de la Universidad Icesi.

1 Experiencia propia. 
"Hablar de discriminación laboral, es hablar más allá del acceso al mercado laboral, de la igualdad salarial, los contratos, (...); es referirse a profundas estructuras sociales y culturales que conllevan dinámicas de racismo y exclusión" dice Villarraga, investigador del Observatorio contra la Discriminación y el Racismo (OCDR), quien además insiste en que la segregación espacial ocupa un lugar importante a la hora de explicar la discriminación (OCDR, 2012:4). Pues, según él, el mercado laboral basa sus preferencias en los individuos más capacitados. Razón por la cual, cobra importancia el capital humano. Y con ello, la ubicación espacial de los individuos (OCDR, 2012). Pues, es a partir de ésta que los individuos tienen acceso a bienes, servicios materiales y servicios culturales que permiten, en su conjunto, obtener el conocimiento y las capacidades necesarias para la inserción laboral (OCDR, 2012).

En esa medida, el hecho de que más de la mitad de la población afrocolombiana, en Cali, se ubique en los sectores más marginales de la ciudad implica, por ende, que la superación de la pobreza y el acceso a las oportunidades económicas, a través del capital material, sea poco probable (OCDR, 2012). Probabilidad que coincide con el testimonio de Ernestina, mujer negra del distrito de Aguablanca, quien es entrevistada por Ana Cortés y Evelin Carranza, trabajadoras sociales de la universidad del Valle (Cortés Castillo y Carranza Gómez, 2012). Pues, ella hace declaraciones como ésta: "Sabe trabajar, porque una mujer inútil, mejor dicho, (...) ¿Qué sabe hacer? Es lo primero que le preguntan a usted: ¿sabe manejar un computar? Si le dice no, no sirve" (Cortés Castillo y Carranza Gómez, 2012: 218).

Bajo la misma línea argumentativa que sostiene Villarraga, se encuentra que cuando a la población afrocolombiana se le ubica en sectores marginales, se le asocia a situaciones y lugares de pobreza, privilegiando un imaginario sobre las capacidades y labores a las que tienen, "supuestamente", predisposición estas personas (OCDR, 2012). Siendo esto un caso de discriminación que, consecuente de la falta de capital humano, permite explicar el por qué las mujeres negras no tienen cabida en espacios laborales distintos a la cocina y al trabajo doméstico (OCDR, 2012).

"Por lo menos por ser mujer negra nos dicen que servimos mucho para hacer un buen sancocho de pescado, que somos las mejores cocineras", dice Ernestina (Cortés Castillo y Carranza Gómez, 2012: 215:215). 
Testimonio que me hace reflexionar sobre la sutileza con la que se incurre en las prácticas discriminatorias contra la mujer afro. Y que, para mi sorpresa, se mantiene y se refuerzan a partir de prácticas cotidianas que pasan desapercibidas (ENS, s.f.). Es decir, ¿cuántas veces no hemos dicho, por ejemplo, "trabaja como negra"?, entre otras muchas expresiones generalizadas por el sentido común, que insinúan y sin intención, por lo menos en mi caso, justifican la vulneración a los derechos de la población afro (ENS, s.f.).

Por otro lado, vale la pena preguntarse ¿A qué se debe la brecha salarial entre las mujeres no afro y afro, cuando estas últimas han logrado conseguir el capital humano necesario para la inserción laboral?

Si las diferencias en los salarios no se determinan por las dotaciones en capital humano, se podría deducir que existe un trato desigual e injusto referido a aspectos que no afectan la productividad potencial de los individuos (González-Rivas, 2012). Un artículo de Nazly González plantea que lo anterior es un fenómeno comúnmente denominado como discriminación. Su argumento consiste en demostrar que la discriminación tienen que ver con el prejuicio de los empleadores sobre la población afrocolombiana, que en el caso particular de las mujeres, cargan con un peso histórico desfavorable asociado a su grupo, que no le permite transmitir credibilidad en su desempeño laboral (González-Rivas, 2012).

Este es el caso de María, mujer negra que hace parte de los testimonio de la escuela nacional sindical, que, antes de ser docente, pasó por todo tipo de trabajos (ENS, s.f.). Trabajos, donde siendo la persona más calificada profesionalmente, tenía la remuneración más baja (ENS, s.f.).

En "Conseguir trabajo siendo indígena o afro es un verdadero "camello", Alda Mera, reportera del país, nombra a Aurora Vergara, directora del Centro de Estudios Afrodiaspóricos (Ceaf) de la Universidad ICESI, y a Marianella Ortiz, estudiante de maestría de la misma universidad, a fin de corroborar la existencia de las diferencias salariales que, según el grado de escolaridad y la etnia, se presenta entre las mujeres (Mera, 2014).

Los resultados fueron contundentes, una bachiller no afro gana \$6851 PCO más que una mujer afro en las misma condiciones; entre las universitarias, la situación es 
la misma, solo que esta vez la mujer afro gana \$254.928 PCO menos; y ni que hablar de las mujeres que se logran especializar, donde las mujeres no afro ganan $\$ 310.368$ PCO más que las afro (Mera, 2014).

Estos resultados corroboran el argumento mencionado de Nancy González, pero también exponen el otro lado de la moneda. Lado que a pesar de ser diferente, no significa que la exclusión haya mermado (Mera, 2014). Pues, el hecho de que solo las mujeres de maestría afro ganen $\$ 443.970$ PCO más que las no afro, es consecuente, según lo señala Ortiz, de que las empresas vean en estas mujeres un mayor grado de productividad. Productividad que les ha permitido llegar a alcanzar dicho nivel educativo, superando así sus límites (Mera, 2014).

La discriminación de las mujeres afro, en últimas, no hace referencia solo a las escazas probabilidades que éstas tienen, en términos del capital humano, para acceder a buenos empleos. Pues, queda más que claro que la sociedad colombiana, sociedad patriarcal, de clases, en una palabra, discriminadora ha transformado la identidad de estas mujeres a múltiples prejuicios. Prejuicios que permiten estigmatizar a este grupo y, por ende, dar origen a la exclusión. Por consiguiente, considero que si bien la responsabilidad es de la sociedad, el Estado debe empezar a promover políticas más inclusivas que, orientadas hacia las necesidades de estas mujeres, les garantice mejores servicios que les permita desarrollar su potencial. No obstante, dichas políticas no debe dejar de lado al resto de actores que conforman la sociedad, pues solo si integran todos los actores de la sociedad, se puede generar un cambio permanente y positivo.

Por ahora, en lo que se da el cambio, debemos ser nosotras, las mujeres no afro, especialmente, las catalogadas como blancas, las que iniciemos un proceso de acompañamiento con estas mujeres. Pues, si bien es cierto que nosotras no somos discriminadas por nuestra etnia, todavía, tras la llegada de la modernidad que nos permitió trabajar, vivimos momentos de exclusión. Una exclusión que si bien no es étnica, es de género. Razón por la cual, considero que esta semejanza, deber ser el motor que nos permita, a nosotras como mujeres, luchar tanto por acabar con la discriminación, como lograr todos los intereses que como mujeres compartimos. 


\section{Bibliografía}

Observatorio contra la discriminación y racismo - OCDR (2012). Discriminación laboral en Cali (segundo informe). Recuperado mayo, 16, 2015 de https://www.mininterior.gov.co/mision/direccion-de-asuntos-para-comunidades-negras-afrocolombianas-raizales-y-palenqueras/observatorio-de-discriminacion

Cortés Castillo, Ana Cristina y Evelin Yohana Carranza Gómez (2012). Ser mujer negra en Sardi. Construcción de la identidad femenina. Recuperado mayo, 16, 2015 de:http://bibliotecadigital.univalle.edu.co/bitstream/10893/6335/1/8\%20Ser\%20mujer\%20negra\%20 en\%20Sardi.\%20Construcción\%20de\%20identidad\%20femenina.pdf

Escuela Nacional Sindical - ENS (n,d). La población afrocolombiana sufre mayor déficit de trabajo decente y exclusión labora: según estudio realizado en Cartagena, buenaventura, Cali y Medellin. Recuperado mayo, 16, 2015 de http://ens.org.co/apcaa-files/4e7bc24bf4203c2a12902f078ba45224/rese_aAfr.pdf

González-Rivas, Nazly (2012). "Discriminación salarial: un análisis entre mujeres afrocolombianas y no afrocolombianas en el área metropolitana de Cali". Revista Latinoamericana de Ciencias Sociales, Niñez y Juventud, 10(1), 563-578. Retrieved May 16, 2015, de http://www.scielo.org.co/scielo.php?script=sci_arttext\&pid=S1692$715 \mathrm{X} 2012000100036 \& \operatorname{lng}=$ en\&tlng $=\mathrm{es}$

Mera, Alda (2014). "Conseguir trabajo siendo indígena o afro es un verdadero 'camello"'. El País. Recuperado mayo, 16, 2015 de http://www.elpais.com.co/elpais/ cali/noticias/odisea-conseguir-empleo-siendo-indigena-o-afro 